\title{
Data Mining and Polar Coordinates in the Analysis by Gender of Finishing Behaviors in Professional Basketball Pick and Roll
}

\author{
Juan Pablo Morillo-Baro ${ }^{1}$, Belén Troyano-Gallegos ${ }^{1}$, José Luis Pastrana-Brincones ${ }^{2}$, \\ Juan Antonio Vázquez-Diz' ${ }^{1}$, Rafael E. Reigal ${ }^{1}$, Yarisel Quiñones-Rodríguez ${ }^{3}$, \\ Antonio Hernández-Mendo ${ }^{1}$, Coral Falcó ${ }^{4 *}$ and Verónica Morales-Sánchez ${ }^{1}$ \\ ${ }^{1}$ Department of Social Psychology, Social Work, Anthropology and East Asian Studies, University of Málaga, Málaga, Spain, \\ ${ }^{2}$ Department of Languages and Computer Science, University of Málaga, Málaga, Spain, ${ }^{3}$ Department of Sports Dididactics, \\ University of Pinar del Río Hermanos Saín Montes de Oca, Pinar del Río, Cuba, ${ }^{4}$ Department of Sport, Food and Natural \\ Sciences, Western Norway University of Applied Sciences, Bergen, Norway
}

OPEN ACCESS

Edited by:

Bruno Travassos,

University of Beira Interior, Portugal

Reviewed by:

Rubén Maneiro,

Pontifical University of

Salamanca, Spain

Miguel Pic,

South Ural State University, Russia

*Correspondence:

Coral Falcó

coral.falco@hvl.no

Specialty section:

This article was submitted to Movement Science and Sport

Psychology,

a section of the journa

Frontiers in Sports and Active Living

Received: 16 July 2021 Accepted: 01 November 2021

Published: 08 December 2021

Citation:

Morillo-Baro JP, Troyano-Gallegos B, Pastrana-Brincones $\mathrm{J}$,

Vázquez-Diz JA, Reigal RE,

Quiñones-Rodríguez Y,

Hernández-Mendo A, Falcó C and

Morales-Sánchez V (2021) Data Mining and Polar Coordinates in the

Analysis by Gender of Finishing

Behaviors in Professional Basketball

Pick and Roll.

Front. Sports Act. Living 3:742609.

doi: 10.3389/fspor.2021.742609
The open nature of basketball gives it a large uncertainty that makes hard the tactical analysis of the situations that happen in the game. Specifically, screens are one of the offensive tactical elements most used in basketball and one example of a tactical situation that needs the highest preparation level to get a good performance in the competition. The aim of this study is to differentiate these player behaviors by gender using data mining and polar coordinates analysis. Therefore, one ad hoc observational tool made by 17 criteria and 97 exhaustive and mutually exclusive (E/ME) categories has been designed and validated using the data quality analysis (correlation coefficients and concordance index 0.98) and generalizability analysis ( $G$ coefficients 0.94 ) to perform such a study. The observational design is nomothetic, punctual, and multidimensional. A total of 176 ball screens situations have been analyzed for the men's category and 118 for women's category, corresponding to three different teams of each gender playing in the highest competition level in Spain during the 2018/2019 season using Hoisan software tool. The analysis of the relationships among behaviors has been performed using Polar Coordinates analysis as well as data mining analysis: clustering and decision tree classifier. Results show significant relationships that allow us to tactically interpret the pick and roll situations in men's and women's professional basketball players in Spain, allowing us to develop more intervention programs which will optimize training and improve players performance.

Keywords: mixed method, systematic observation, polar coordinates, data mining, basketball

\section{INTRODUCTION}

Cooperative-opposition collective sports, such as basketball, are characterized by a high motor interaction and a high degree of uncertainty in those interactions (Castellano and Hernández Mendo, 2000; Castellano et al., 2009; Conejero et al., 2016) because during a game there are interactions with both teammates and opponents. Therefore, although it is a sport that has been studied from many fields of knowledge such as biomechanics (Morales Toapanta et al., 2018), psychology (Rodríguez López and Sáez Rodríguez, 2009), or physiology (Calleja et al., 2008), 
it is important that it also be analyzed from a perspective where motor interaction is taken into account (Hernández-Mendo et al., 2000) because the protagonists are the players and their technical-tactical reading.

In recent decades, basketball has experienced a progressive increase in physical, technical, and tactical demands in competition (Sarmento et al., 2017). Together with the study of the game situations carried out by the technical staff, has made harder to obtain offensive advantages to score points and perform at the highest level. So it is tried to take advantage from each phase of the game to improve the performance (Morillo-Baro et al., 2020). High level of intensity requires an optimal physical preparation and an extensive technical-tactical background for the players that allows them to adapt to the continuously changing environments they face (Morillo-Baro et al., 2020).

Pick and roll is a collective offensive resource frequently used in the offensive phase throughout the game, being present in $\sim 30-45 \%$ of positional attacks (Nunes et al., 2016; Romarís Durán, 2016). Numerous studies have investigated the importance of this tactical procedure in high-level basketball (Koutsouridis et al., 2018; Nunes et al., 2021; Sekulić, 2021). It is so important that it is the most used action to end attacks in Liga ACB, and the second most used, after the individual play, in Liga Femenina (Romarís Durán et al., 2013). It is defined as the collective action of the two-on-two $(2 \times 2)$ game in which the attacker without the ball performs a screen (hinders an opponent by placing himself in his path) helping his/her mate who is having the ball (Cárdenas, 2010; Muñoz Arroyave et al., 2015; Nunes et al., 2016). Therefore, studying it combined with other tactical behaviors is a matter of great interest for coaches who aim to optimize the game performance of the team (Nunes et al., 2016; Morillo-Baro et al., 2020). It is also important to study the behavior in training situations, during formative stages with young players, in line with the studies developed by Mateus et al. (2019, 2020), modifying the dimensions of the game space or in simulated game situations.

Mixed methods and observational methodology has got high importance in recent decades in the sport context (Anguera and Hernández-Mendo, 2015; Anguera et al., 2021). Its applicability in the natural context of high-performance sport creates an optimal relationship between science and practical application, focusing on the spontaneous and habitual behavior of the observed participants (Anguera, 1990; Anguera and Hernández-Mendo, 2013; Sánchez-Algarra and Anguera, 2013). Added to the possibility of developing ad hoc observation instruments (Sarmento et al., 2010) adapted to the reality of a given context, it allows a detailed analysis of the behaviors involved in the tactical development of the game.

This combination of quantitative and qualitative data represents the essence of mixed methods, transforming data from qualitative to quantitative and vice versa, and interpreting the results after analysis (Cresswell and Plano Clark, 2011). An example of this is the observational methodology itself (Anguera and Hernández-Mendo, 2016) together with its distinctive analyses such as polar coordinates analysis (Vázquez-Diz et al., 2019; Morales-Sánchez et al., 2020) and also data mining (Pastrana et al., 2019). These techniques have shown to be very useful in sport psychology to explore several variables usually studied in this field of knowledge, getting useful information on how scores are distributed and groups are classified (Pastrana et al., 2019; Vázquez-Diz et al., 2019; Reigal et al., 2020), and studying the relationships established between the behaviors that occur (Nunes et al., 2016; Morillo-Baro et al., 2020).

Data mining is considered a set of techniques and technologies that allows extracting useful information from a large data set, such as patterns and trends. It attempts to find patterns of behavior in large data sets to explain them (Pastrana et al., 2019). Clustering is one of the most used techniques in data mining. Basically, it is the task of dividing the population into a number of groups such that elements in the same group are more similar but different from those in the other groups. In other words, the aim is to segregate groups with similar traits and assign them into clusters. The k-means clustering algorithm (Likas et al., 2003) is one of the most used algorithms for clustering, to cluster observations into groups of related observations without any prior knowledge of those relationships. Thus, it becomes a very useful tool because it allows us to find or identify unknown groups that are often not otherwise identified (Zaki and Meira, 2014; Witten et al., 2016).

This clustering technique is also used as a prestep for several algorithms, such as "classification" or "attribute selection," which would perform better and faster on a smaller selected set of attributes (Dutt et al., 2015; Thomas et al., 2018). The J48 algorithm (Bhargava et al., 2013) is used to classify different data to get accurate results of the classification. The J48 algorithm is one of the best machine learning algorithms to examine the data categorically and continuously. The J48 decision tree algorithm is a classification tool (Kaur et al., 2015) that creates an acyclic graph structure (a tree), where attributes are represented at internal nodes and arcs, representing how the values are divided. Each leaf node will be a value of the target class. Decision trees are often built from a training set and then used as a model of the problem to predict future behavior.

On the other hand, the polar coordinate technique uses a sequential prospective and retrospective lag analysis of the recorded behaviors (Sackett, 1980; Anguera et al., 1997). It allows a drastic reduction of the analyzed data and a graphical representation of the established relationships between focal and conditioned categories through a vector system (HernándezMendo and Anguera, 1999). The contrast statistic of this analysis is the Zsum (Zsum $=\Sigma z / \sqrt{ } n$, where $n$ is the number of lags) (Cochran, 1954). The distribution of this parameter Zsum has a $x=0$ and an $\mathrm{Sx}=1$. The relationships between behaviors and their vector representation are obtained from these values. A value is considered statistically significant when the vector module is equal or greater than 1.96. This value is estimated through the square root of the sum of the square of the Zsum of the $X$ (prospective) and the square of the Zsum of the 
$Y$ (retrospective):

$$
\text { Module }=\sqrt{Z_{\text {sumP }}^{2}+Z \text { zsumR }}{ }^{2}
$$

The angle of the vector $(\phi=$ Arc sine of $Y /$ Radius) will determine the excitatory or inhibitory nature of the relationship (Castellano and Hernández-Mendo, 2003).

Considering the possibilities offered by data mining and polar coordinates analysis, the objective of this work is to extract patterns from the data to explain and predict the behaviors occurring in the execution of the tactical means of ball screen in professional basketball in Spain, differentiating it according to gender.

\section{MATERIALS AND METHODS}

\section{Research Design}

This study has been carried out using a design located in the fourth quadrant of a nomothetic, punctual, and multidimensional nature, according to the proposal of Anguera et al. (2011). Nomothetic due to the analysis of several teams, punctual because it is the registration of several games but of different teams in the regular phase, and multidimensional because several dimensions have been observed that correspond to the various criteria of the observational tool. Furthermore, since the observer does not interact with the subjects, it is a nonparticipant observational process (Anguera et al., 2000).

\section{Participants}

In this work, three men's teams (FC Barcelona Lassa, Unicaja and Valencia Basket) of the ACB league and three women's teams (Perfumerías Avenida, Girona FC and Lacturale Araski) of basketball of the 2018-2019 season were chosen, and a total of three games of each category in the regular phase were analyzed. Finally, 176 ball screen situations from the ACB League and 117 ball screen situations from the Women's League were observed and coded.

According to the Belmont Report and the standards of competence, since the videotapes that we have analyzed for this study are in the public domain, it has not been necessary to obtain informed consent from the participants. The Belmont Report describes basic ethical principles and guidelines concerning ethical issues in human subject research. According to these guidelines, images of public behavior can be used for research without getting the informed consent of the athletes (American Psychological Association, 2002). We analyzed games belonging to the official professional basketball competition in Spain (ACB League and Women's League) that was broadcast on public television (Movistar+, 0 and TDP), hoping for a capacity audience.

\section{Instruments}

To conduct this work, Hoisan software (Hernández-Mendo et al., 2012, 2014) was used to code and record the behaviors, perform the data quality analysis, and the polar coordinates analysis. The optimization of the graphical representation of the polar coordinates analysis has been performed with the $\mathrm{R}$ program (Rodríguez-Medina et al., 2019), and SAGT program (Hernández-Mendo et al., 2016) has been used for the generalizability analysis.

To carry out this work, a first ad hoc observational tool, called the Tactical Assessment of Ball Screen in Basketball (VTBDB), was created with the HOISAN software (Hernández-Mendo et al., 2012) with the aim of observing, coding, and analyzing ball screen in basketball. Once this tool was created, several games were observed to improve it. Finally, the tool is composed of 17 criteria and a total of 97 categories, as shown in Table $\mathbf{1 .}$

The observational instrument has passed the data quality tests required by observational methodology. Table 2 shows the results of Kendall's, Pearson's, and Spearman's Tau $b$ correlation coefficients, reaching minimum indexes of 0.988 , and Cohen's Kappa index shows a minimum value of 0.987 .

The generalizability theory (Cronbach et al., 1972; Cardinet et al., 1976, 1981) allows to control the adequate quality of the data coming from the $\mathrm{MO}$ and to establish an accurate estimation of the different sample sizes (Blanco-Villaseñor et al., 2014).

To test intra- and interobserver reliability, a two-facet, category and observer $(\mathrm{C} / \mathrm{O})$ design has been used. The results obtained by the SAGT program showed that both intraobserver and interobserver variability was associated with the category facet at 99.39 and $93.32 \%$ respectively, being 0 for the observers facet and 0.60 and $6.67 \%$ in the interaction of the categoriesobserver facets. Table 3 shows the values associated with each facet.

A two-facet design, observers and categories $(\mathrm{O} / \mathrm{C})$, has been also carried out for the homogeneity analysis of the tool. This design ascertains the degree of differentiation among the different actions of the game using the proposed categories. The results showed that variability is $99.39 \%$ associated with the category facet, $0.60 \%$ for the observers/categories interaction, and $0.00 \%$ for the observer facet. Since the generalization coefficients tend to zero, the homogeneity of the categories can be admitted to be optimal in the sense of differentiators (Blanco-Villaseñor et al., 2014).

The estimation of the minimum number of sessions to be observed to generalize with optimal precision has been performed using a two-facet design, categories and matches $(\mathrm{C} / \mathrm{P})$. Finally, an absolute $G$ coefficient of 0.949 was obtained when analyzing the three matches. Table 4 shows the obtained values in the $G$ coefficients according to the matches to be observed. It was decided to carry out three observations for each of the categories (men and women).

\section{Procedure}

Once the tool has been validated and the reliability of the observers has been estimated by means of the data quality and generalizability analyses, the observations of the six matches have been coded and the polar coordinate analyses have been carried out using the HOISAN program (Hernández-Mendo et al., 2012).

First, a sequential analysis of all observations made with the selected focal behavior has been performed, obtaining the $Z$ results with a delays range between -5 and 5 . Calculations were made to determine the Zsum parameters (prospective and retrospective), the quadrant assignment, the module, the 
TABLE 1 | Observation instrument for the tactical assessment of ball screen in basketball (VTBDB).

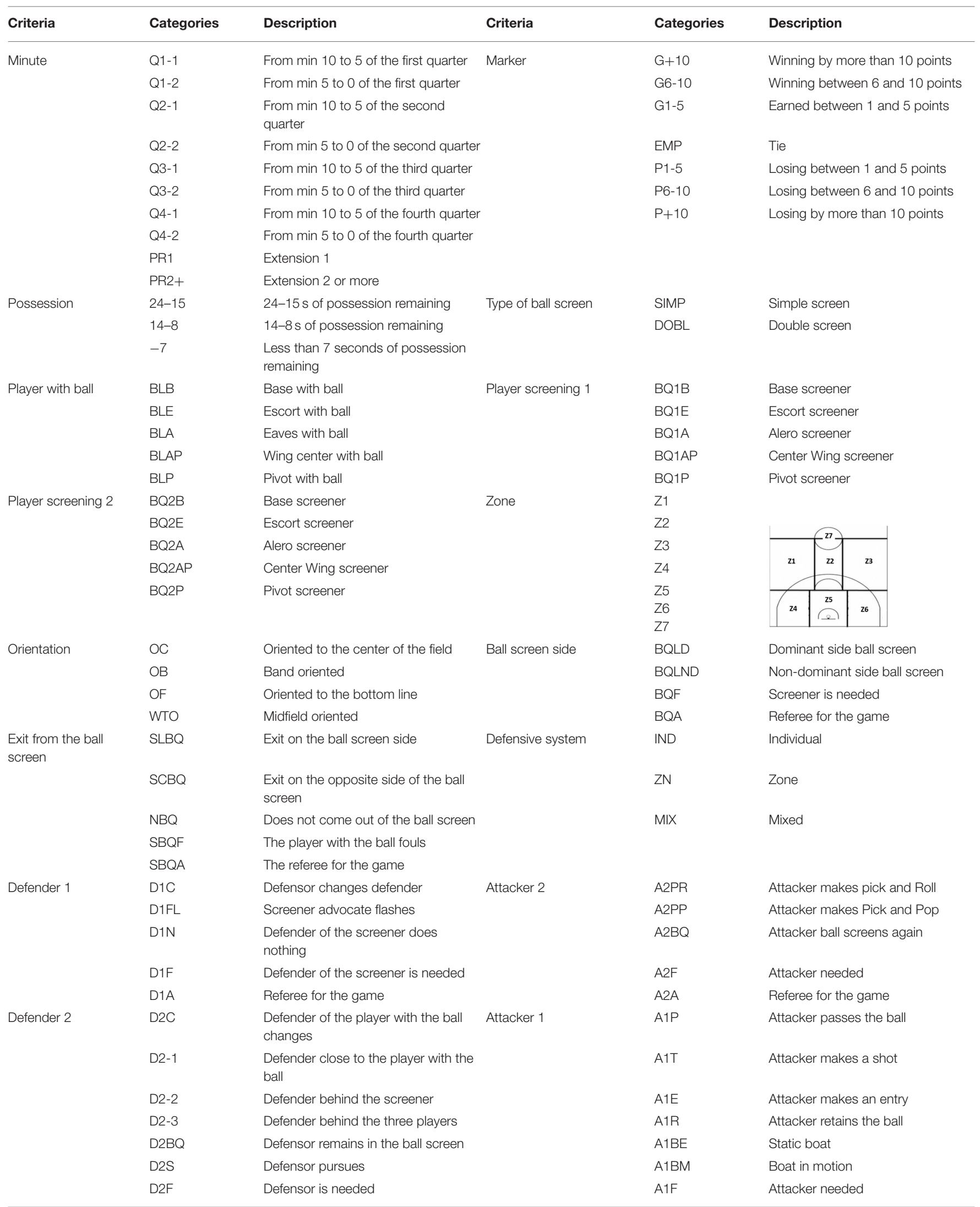


TABLE 1 | Continued

\begin{tabular}{|c|c|c|c|c|c|}
\hline Criteria & Categories & Description & Criteria & Categories & Description \\
\hline & D2A & Referee for the game & & A1A & Referee for the game \\
\hline \multirow[t]{8}{*}{ Final } & PV & Advantageous pass & & & \\
\hline & EV & Advantageous entry & & & \\
\hline & TV & Advantageous shot & & & \\
\hline & TD & Disadvantageous shot & & & \\
\hline & PERD & Loss of possession & & & \\
\hline & FD & Foul of the defense & & & \\
\hline & FA & Attack foul & & & \\
\hline & ARB & Referee for the game & & & \\
\hline
\end{tabular}

TABLE 2 | Values of correlation coefficients and concordance index.

\begin{tabular}{lcc}
\hline Coefficient & $\begin{array}{c}\text { Intra } \\
\text { (Obs. 1 vs. Obs. 1 bis) }\end{array}$ & $\begin{array}{c}\text { Concordance inter } \\
\text { (Obs. 1 vs. Obs. 2) }\end{array}$ \\
\hline Pearson & 0.999 & 0.999 \\
Spearman & 0.991 & 0.992 \\
Kendall's Tau b & 0.988 & 0.988 \\
Cohen's Kappa & 0.987 & 0.988
\end{tabular}

angle, and the transformed angle for the rest of the categories (Castellano and Hernández-Mendo, 2003) using these values. The characterization of each quadrant is as follows (Castellano and Hernández-Mendo, 2003):

Quadrant I $[+,+]$ : Criterion behavior is excited with respect to mating behavior in the retrospective and prospective perspective.

Quadrant II $[-,+]$ : The criterion behavior has a relationship with respect to the mating behavior of excitation in retrospective perspective and inhibition in prospective perspective.

Quadrant III [-,-]: The criterion behavior has a relationship with respect to inhibition mating in the retrospective and prospective perspective.

Quadrant IV [+,-]: The criterion behavior has a relationship with the mating behavior of excitation in prospective perspective and inhibition in retrospective perspective.

Two behaviors have been selected as focal (given): Exit on the opposite side of the ball screen (SCBQ) and exit on the side of the ball screen (SLBQ).

Subsequently, the gender-differentiated data matrices have been used for data mining analysis (Weka 3, 2021). This type of analysis has made it possible to establish relationships between attributes or data sets, group similar data, classify attribute relationships, and show information that might be hidden or lost in a large amount of data not mined.
TABLE 3 | Values associated with each facet in intra- and inter-observer reliability.

\begin{tabular}{llll}
\hline & $\%[\mathbf{0}]$ & $\%[\mathbf{C}]$ & $\%[\mathbf{O}]$ [C] \\
\hline Intraobserver variability & 0.000 & 99.394 & 0.606 \\
Interobserver variability & 0.000 & 93.321 & 6.679 \\
\hline
\end{tabular}

TABLE 4 | Evolution of G coefficients as a function of the number of matches to be observed.

\begin{tabular}{llc}
\hline & 2 matches & 3 matches \\
\hline Relative G coefficient & 0.932 & 0.953 \\
Absolute G coefficient & 0.925 & 0.949 \\
\hline
\end{tabular}

\section{RESULTS}

\section{Polar Coordinates}

The polar coordinates analysis shows the results for each gender (male and female) in two-ball screens, on the one hand, the focal behavior "output on the opposite side of the ball screen" (SCBQ) and on the other hand, the "output on the side of the ball screen" (SLBQ).

Table 5 shows the relationship among the focal behavior SCBQ with the rest of the mating behaviors for all the observations made for each gender.

Related to the starting focal behavior "on the opposite side of the ball screen" (SCBQ), the results show the following significant relationships in quadrant I: BLE (guard with the ball), BLA (forward with the ball), and D2-1 (defender close to the player with the ball) for the male category; and Q2-2 (from min 5 to 0 of the second quarter), D2-2 (defender behind the screener), and D2-3 (defender behind the three players) for the female category. In quadrant II, Q1-1 (from min 10 to 5 of the first quarter) and G1-5 (winning by between 1 and 5 points) are shown as significant behaviors for the male category; and for the female category Q2-1 (from min 10 to 5 of the first quarter), TD (disadvantageous shot) and PERD (loss of possession). In quadrant III, the pairing behaviors P6-10 (losing between 6 and 10 points) and $\mathrm{P}+10$ (losing more than 10 points) are significant 
TABLE 5 | Significant relationships and vector representation between SCBQ focal behavior and mating behaviors for each gender.

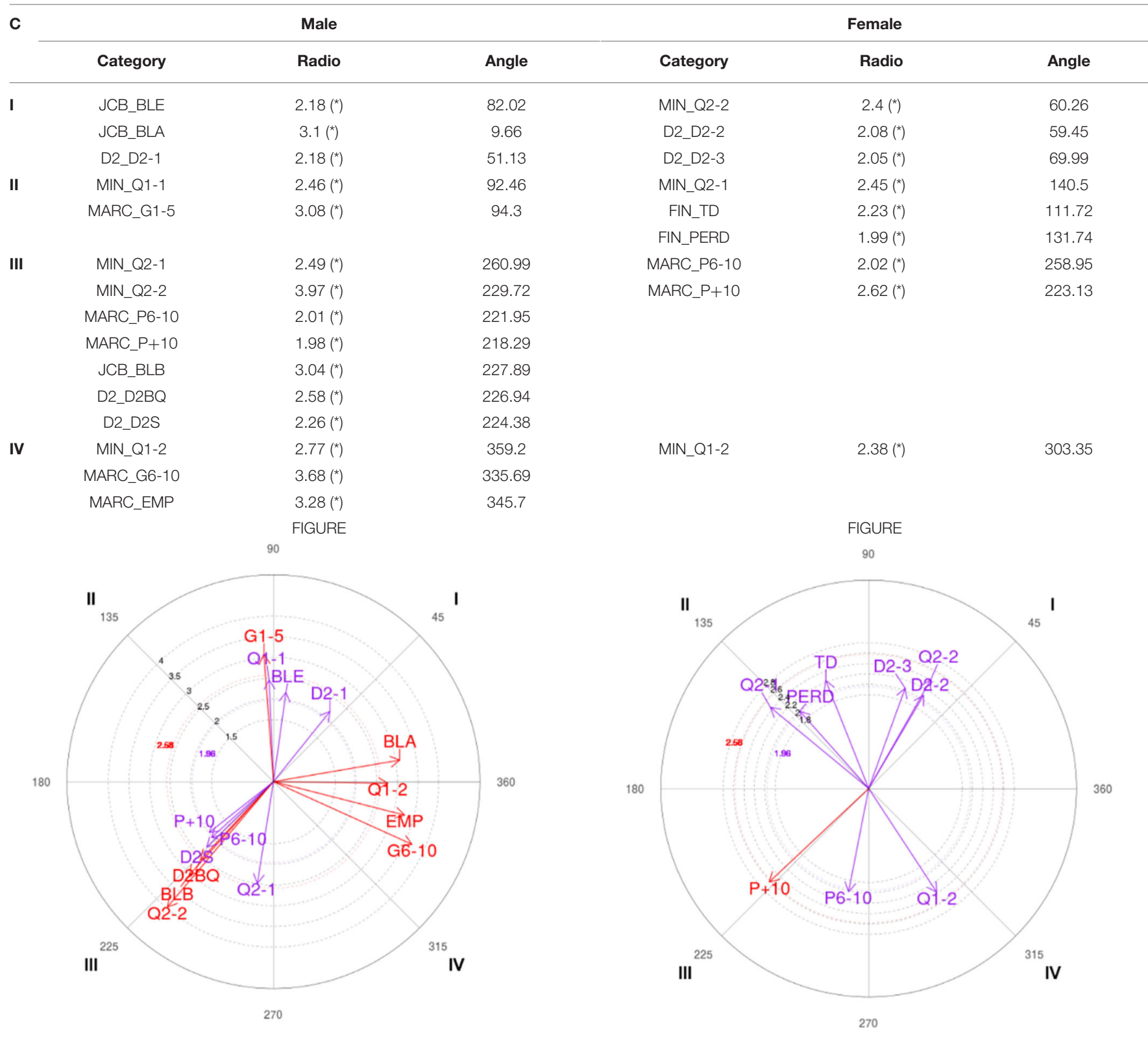

Significant relationships: ${ }^{*} p<0.05$ vector $\geq 1.96$.

for both the male and female categories. In the male category, the behaviors Q2-1 (from min 10 to 5 of the second quarter), Q2-2 (from $\min 5$ to 0 of the second quarter), BLB (base with ball), D2BQ (defender stays in the ball screen), and D2S (defender chases) are also significant. Finally, quadrant IV shows the conditioned behaviors G6-10 (winning from 6 to 10 points) and EMP (tie) for the male category, and Q1-2 (from min 5 to 0 of the first quarter) for both categories.

Table 6 below shows the results of the polar coordinate analysis for the SLBQ focal behavior (ball screen side exit).

The results of the polar coordinates analysis for the focal behavior of the SLBQ show several significant relationships for each category. In the first quadrant, for the male category, behaviors Q2-1, Q2-2, BLB, D2BQ, and D2S are significant. In contrast, the female category does not show significant relationships with any of the mating behaviors. In quadrant II, the significant conditioned behaviors are: G6-10, EMP (tie) and D1C (defender changes defender) for the male category; and Q41 (from min 10 to 5 of the fourth quarter) for the female category. In the third quadrant are Q1-1, BLA, and D2-1 (defender sticking to the player with the ball) for the male category, and Q2-2 and G6-10 for the female category. Finally, in quadrant IV, the behaviors G1-5 (winning between 1 and 5 points) and BLE (guard with the ball) are significant for the male category; and Q2-1 
TABLE 6 | Significant relationships and vector representation between SLBQ focal behavior and mating behaviors for each gender.

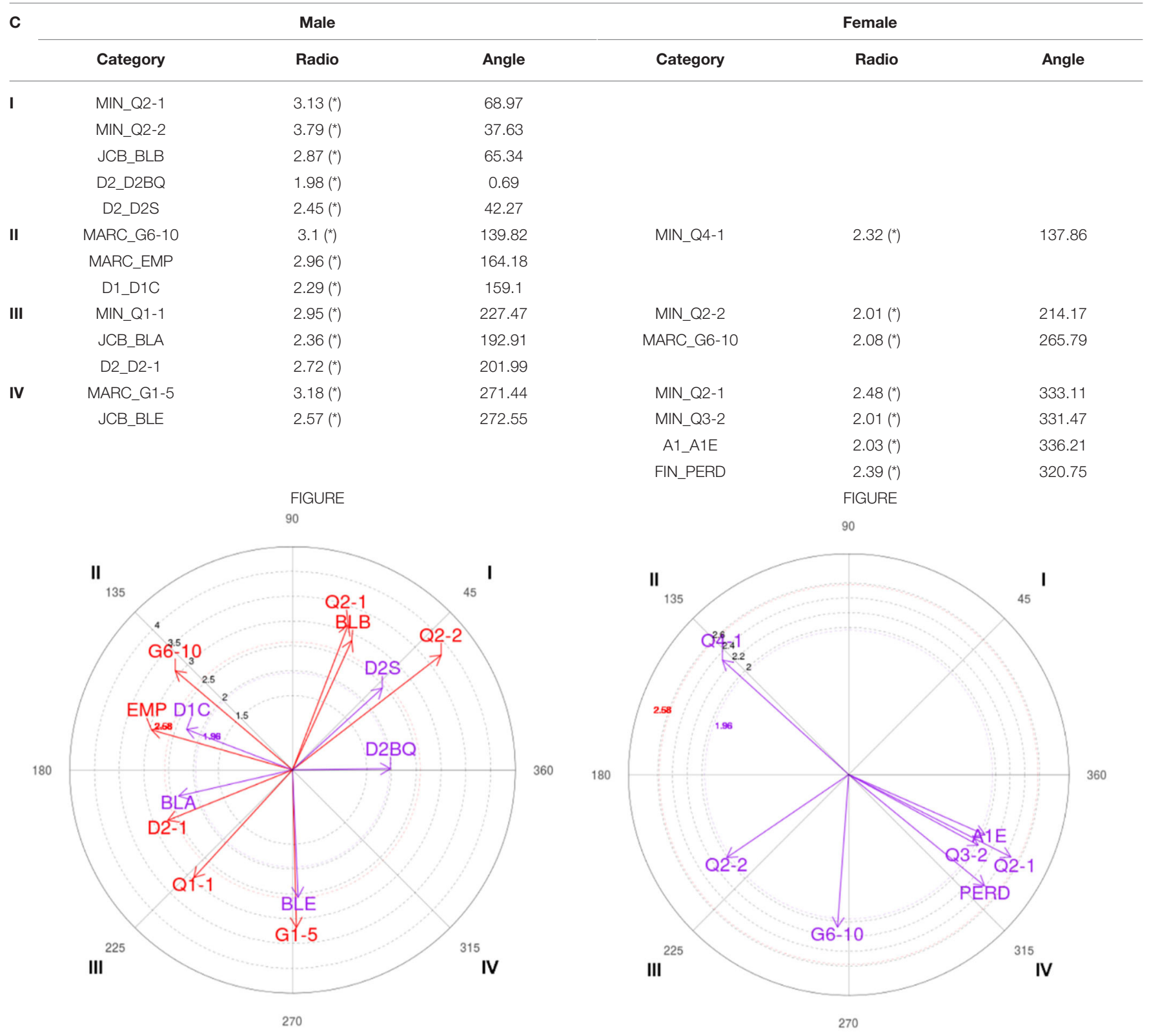

Significant relationships: ${ }^{*} p<0.05$ vector $\geq 1.96$.

(from min 10 to 5 of the second quarter), Q3-2 (from min 5 to 0 of the third quarter), A1E (attacker makes a shot), and PERD (loss of possession) for the female category.

\section{Data Mining}

An analysis technique known as clustering has been used, which allows the identification of typologies or groups where the elements are very similar to each other and very different from those of the other groups. K-means algorithm has been used for this clustering, which is an algorithm classified as a partitioning and repositioning method. This algorithm is so far the most widely used in scientific and industrial applications. The name comes from the fact that it represents each of the clusters by the average (or weighted average) of its points, i.e. by its centroid. The centroid representation has the advantage that it has an immediate graphical and statistical significance. The sum of the discrepancies between a point and its centroid, expressed through the appropriate distance, is used as the objective function. The objective function, sum of the squares of the errors between the points and their respective centroids, is equal to the total variance within the cluster itself. The sum of squares of the errors can be rationalized as the negative of the log-likelihood for mixed models using normal distributions.

Each cluster represents a "quotient set." Table 7 shows cluster 0 as the most representative cluster. 
TABLE 7 | Results of the clustering of data.

\begin{tabular}{lcccc}
\hline Attribute & $\begin{array}{c}\text { Cluster\#0 } \\
(\mathbf{1 2 5 . 0 )}(\mathbf{4 3} \%)\end{array}$ & $\begin{array}{c}\text { Cluster\#1 } \\
\mathbf{( 6 0 . 0 )}(\mathbf{2 1} \%)\end{array}$ & $\begin{array}{c}\text { Cluster\#2 } \\
\mathbf{( 6 1 . 0 )}(\mathbf{2 1} \%)\end{array}$ & $\begin{array}{c}\text { Cluster\#3 } \\
\mathbf{( 4 5 . 0 )}(\mathbf{1 5} \%)\end{array}$ \\
\hline MARC & G1_5 & P1_5 & P6_10 & P6_10 \\
TIP.BQ & SIMP & SIMP & SIMP & SIMP \\
JCB & BLB & BLB & BLB & BLB \\
JBQ1 & BQ1P & BQ1P & BQ1P & BQ1P \\
JBQ2 & NBQ2 & NBQ2 & NBQ2 & NBQ2 \\
ZBQ & Z2 & Z3 & Z3 & Z2 \\
SD & IND & IND & IND & IND \\
ORIBQ & OB & OC & OB & OB \\
LBQ & BQLND & BQLD & BQLND & BQLD \\
SBQ & SLBQ & SLBQ & SLBQ & SLBQ \\
D1 & D1C & D1N & D1N & D1C \\
D2 & D2_1 & D2_2 & D2_1 & D2_1 \\
A1 & A1P & A1P & A1BM & A1BM \\
A2 & A2PR & A2PP & A2PR & A2PR \\
FIN & CONT & CONT & CONT & BV \\
SEX & WOMAN & WOMAN & MAN & MAN \\
\hline
\end{tabular}

The results show that most of the players, regardless of gender, usually make simple ball screens, the player with the ball is the point guard, the screener is the center, there is no second ball screen, the ball screen zones are usually zones 2 and 3 , the defensive system is individual, and the defender is close to the player with the ball.

In women's basketball, normally the attacker having the ball passes it and the second attacker makes a pick and roll or pick and pop. Looking at male players, the attacker having the ball hands it and the second attacker usually makes Pick and Roll. Normally, the situation is completed by continuation of the play in women; whereas men either continue the play or the point guard is the player who creates advantage.

The gender decision tree as a function of factor challenge attributes has a hit ratio of $80 \%$, and it is shown in Figure 1.

The attributes that produce a significance in the sex of the player stand out; these are: MARC (the final score), A1 (ATTACKER 1), A2 (ATTACKER 2), and D1 (DEFENDER 1). Specifically, an interesting result is that only female teams win scoring 10 points more than the other team, but when wining scoring is more than 6 and less than 10 points than the other team, the behavior of attacker 1 is the factor determining the gender. Only female attacker 2 will make a pick and pop compared with a male attacker.

\section{DISCUSSION}

The objective of this work is to identify, by means of data mining and polar coordinates analysis, patterns in the recorded data to explain and predict the behaviors occurring in the execution of the tactical means of ball screen in professional basketball teams in Spain, differentiating it according to gender.
The ad hoc observation tool created has passed the data quality and generalizability analysis tests, which allows a reliable recording of the behaviors appearing during the game action. In addition, it has been shown that polar coordinates analysis is a useful technique for the study of the relationships established between behaviors in a tactical situation in competitive team sports (Vázquez-Diz et al., 2019), and also in data mining analysis to show useful information on how scores are distributed and groups are classified (Art Data Mining and Mixed Methods).

Thus, the results of the different polar coordinates analyses have shown statistically significant differences in mating behaviors between the male and female categories for each of the focal behaviors analyzed.

Ball screen is one of the most used collective offensive resources, present in $\sim 30-45 \%$ of positional attacks (Nunes et al., 2016; Romarís Durán, 2016), reaching in male categories an efficiency percentage of $45 \%$ in attacks in which ball screen is used as a finishing action. In female category they obtain $46 \%$ efficiency, a result that is above the average of positional attacks; so something more should be taken into account in the completion of these attacks (Romarís Durán et al., 2013).

On the other hand, the presence of ball screens in the transition game in Liga Femenina is very scarce; they are used only in $8 \%$. However, ball screen is presented in $31.2 \%$ of transitions to take advantage or causing more advantage in defensive disorganization, reaching an efficiency percentage of 70\% (Romarís Durán, 2016).

Depending on the analysis and interpretation of the data, differences between male and female categories are found in the mating behaviors that show significant relationships with the exit on the opposite side of the ball screen. Although in the male category, the exit on the opposite side of the ball screen shows a relationship of mutual excitement with the defender close to the player with the ball, in the female category the relationship occurs when the defender passes behind the screener and behind the three players. These results coincide with the work conducted by Battaglia et al. (2009) who determined that the most effective defenses performed by the defender of the screened player are to pass behind the player with the ball (pass from second) and to pass behind the three players involved in the ball screen (pass from fourth).

The opposite side of the ball presents a relationship of mutual excitement in the male category with the shooting guard as the attacker with the ball (BLE) and the small forward (BLA), who are players with a percentage of success in the three-point shot of $34.96 \%$ and $33.68 \%$, respectively (Arjonilla López, 2010). This could explain why the defender of the player with the ball leaves the ball screen close to the player with the ball, since it makes it difficult for the attacker to shoot.

On one hand, both categories show a mutually inhibitory relationship between the output on the opposite side to the ball screen and the marker against ( $\mathrm{P} 6-10$ and $\mathrm{P}+10)$, and on the other hand, in male category the marker in favor (G6-10) is inhibited (IV quadrant). A study has shown that the use of pick and roll with the unfavorable marker is bigger (Nunes et al., 2016), but it is unknown if that study took into account ball 


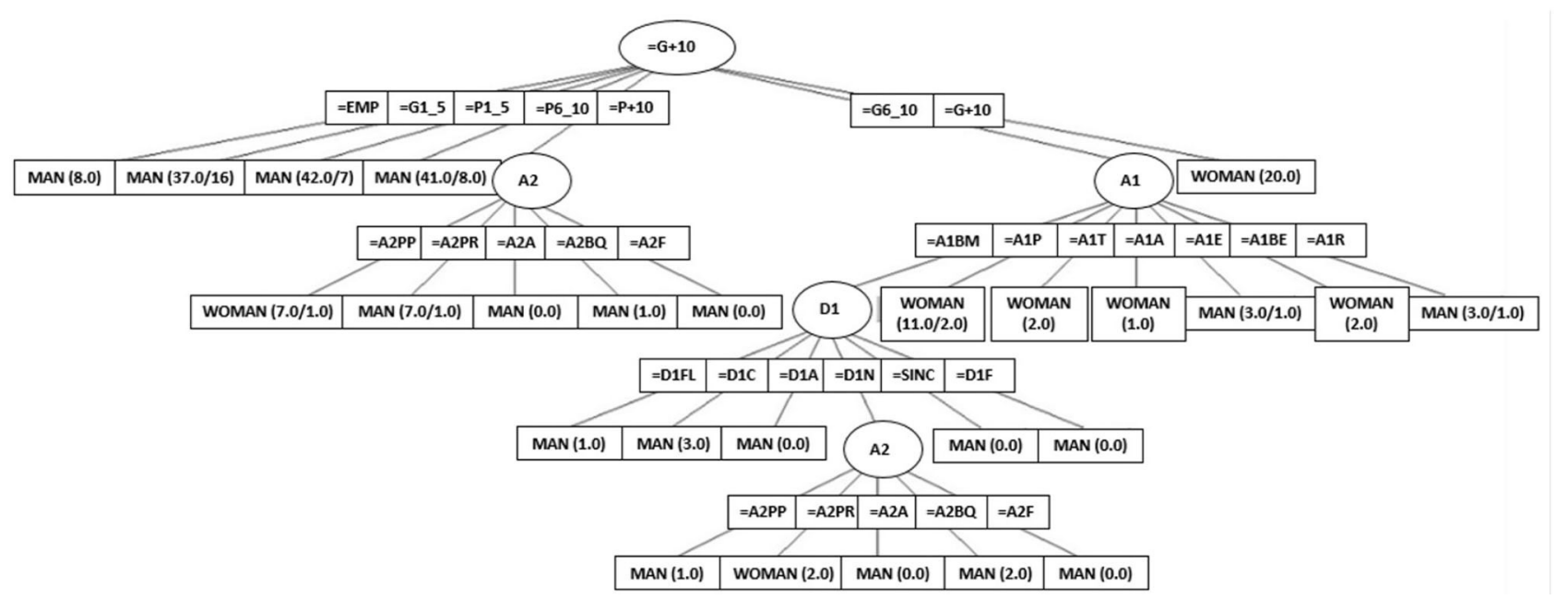

FIGURE 1 | Decision tree.

screens where the player with the ball did not come out on the side of the ball screen.

Looking at the results obtained with the focal behavior, output on the ball screen side and no significant relationships of mutual arousal were found in the female category. On the other hand, a mutually excitatory relationship is shown with the defender chasing and with the defender pinned on the ball screen side for the male category. In addition, in male category the focal behavior is linked inhibiting the marker in favor (G1-5), which could be because of the fact that the use of pick and roll is smaller for a favorable score (Nunes et al., 2016), and in female category it is linked inhibiting the completion of the play by a loss (PERD), which is consistent with the study conducted by Romarís Durán (2016) in which the results showed that ball screen obtains an efficiency of $46 \%$.

The results of the data mining analysis allow to complement and deepen the knowledge of the relationships established between behaviors, showing specifically the tendency to start or finish for each gender in the development of the game situation studied. The female category shows more tactical variety on the part of the second attacker by performing pick and roll or pick and pop at the beginning of the action, whereas the male category focuses on the pick and roll. In the completion of the play, the role of the point guard stands out in the male category as the player who creates advantageous situations for the team in this specific tactical situation.

\section{REFERENCES}

American Psychological Association. (2002). Publication Style Manual of the American Psychological Association (2nd End.). Ciudad de México: El Manual Moderno.

Anguera, M. T. (1990). "Observational methodology," in Metodología de la investigación en ciencias del comportamiento, eds J. Arnau, M. T. Anguera, and J. Gómez-Benito (Murcia: Universidad de Murcia), 125-236.
The study has shown all the virtues of the analysis techniques used; however, it also shows limitations that should be considered, such as the lack of similar studies that would allow the information obtained to be contrasted and compared. Another limitation is not being able to extrapolate the results to competitions in other countries because all the analyzed games belonged to the Spanish basketball leagues (ACB and Liga Femenina).

The findings of both analyses suggest that these techniques are suitable to be applied in sport psychology, specifically to explore different variables that are usually studied in this field of knowledge.

\section{DATA AVAILABILITY STATEMENT}

The raw data supporting the conclusions of this article will be made available by the authors, without undue reservation.

\section{AUTHOR CONTRIBUTIONS}

AH-M, VM-S, RR, JP-B, JM-B, CF, BT-G, and JV-D participated in the study design and data collection, performed statistical analyses and contributed to the interpretation of the results, wrote the manuscript, approved the final manuscript as submitted, and reviewed and provided feedback to the manuscript. All authors made substantial contributions to the final manuscript.

Anguera, M. T., Blanco-Villaseñor, A., Hernández-Mendo, A., and Losada, J. L. (2011). Observational designs: fit and application in sport psychology. Cuad. Psicol. Dep. 11, 63-76.

Anguera, M. T., Blanco-Villaseñor, A., and Losada, J. L. (1997). "Contributions of the polar coordinate technique in mixed designs," in Simposio de metodología de las ciencias del comportamiento (Murcia: University of Murc ia), 583. 
Anguera, M. T., Blanco-Villaseñor, A., Losada, J. S., and Hernández-Mendo, A. (2000). Observational methodology in sport: basic concepts. Read EF Deport. Rev. Digital 24. Available online at: https://www.efdeportes.com/efd24b/obs. htm (accessed January 20, 2021).

Anguera, M. T., and Hernández-Mendo, A. (2013). Observational methodology in the field of sport. E-balonmano.com: Rev. Cienc. Dep. 9, 135-160. Available online at: http://www.e-balonmano.com/ojs/index.php/revista/index (accessed January 20, 2021).

Anguera, M. T., and Hernández-Mendo, A. (2015). Analysis techniques in observational studies in sport science. Cuad. Psicol. Dep. 15, 13-30. doi: $10.4321 /$ S1578-84232015000100002

Anguera, M. T., and Hernández-Mendo, A. (2016). Advances in observational sport science studies from mixed methods. Cuad. Psicol. Dep. 16, 17-30. Available online at: https://revistas.um.es/cpd/article/view/254261 (accessed February 14, 2021).

Anguera, M. T., Portell, P., Hernández-Mendo, A., Sánchez-Algarra, P., and Jonsson, G. K. (2021). "Diachronic analysis of qualitative data," in Reviewer's Guide for Mixed Methods Research Analysis, eds A. J. Onwuegbuzie and B. Johnson (London: Routledge).

Arjonilla López, N. (2010). Incidence of the Factors Distance, Time, Fatigue and Concentration in the Effectiveness in Basketball. (Unpublished doctoral thesis). University of Las Palmas de Gran Canaria, Department of Medical and Surgical Sciences.

Battaglia, O., Sánchez, J. M., Borrás, P. J., and Jiménez, S. (2009). Analysis of Tactics in the Defense of Direct Blocks in the Spanish Professional League. Murcia: V Iberian Basketball Congress.

Bhargava, N., Sharma, G., Bhargava, R., Mathuria, M. (2013). Decision tree analysis on J48 algorithm for data mining. Int. J. Adv. Res. Comput. Sci. Softw. Eng. 3, 1114-1119.

Blanco-Villaseñor, A., Castellano, J., Hernández-Mendo, A., Sánchez-López, C. R., and Usabiaga, O. (2014). Application of GT in sport for the study of reliability, validity and sample estimation. J. Sport Psychol. 23, 131-137.

Calleja, J., Lekue, J. A., Leibar, X., and Terrados, N. (2008). Analysis of lactate concentration in competition in international junior basketball players. Arch. Sports Med. XXV, 11-18.

Cárdenas, D. (2010). Fundamentals of team sports skills: basketball. 227-229.

Cardinet, J., Tourneur, Y., and Allal, L. (1976). The symmetry of generalizability theory: Applications to educational measurement. J. Educ. Meas. 13, 119-135. doi: 10.1111/j.1745-3984.1976.tb00003.x

Cardinet, J., Tourneur, Y., and Allal, L. (1981). Extension of generalizability theory and its applications in educational measurement. J. Educ. Meas. 18, 183-204. doi: 10.1111/j.1745-3984.1981.tb00852.x

Castellano, J., and Hernández Mendo, A. (2000). Sequential analysis in performance football. Psicothema 12, 117-121.

Castellano, J., and Hernández-Mendo, A. (2003). Polar coordinate analysis for the estimation of relationships in motor interaction in soccer. Psicothema $15,569-574$.

Castellano, J., Perea, A., and Hernández-Mendo, A. (2009). "Diachronic analysis of interaction contexts in the 2006 World Cup (212-217)," in Science and foorball VI, eds T. Reilly and F. Korkusuz. London, New York: Routledge.

Cochran, W. G. (1954). Some methods for strengthening the common $X^{2}$ test. Biometrics 10, 417-451. doi: 10.2307/3001616

Conejero, M., Claver, F., Fernández-Echevarría, C., Gil-Arias, A., and Moreno, M. P. (2016). Design and validation of an observation instrument to assess decision making in the reception action in volleyball. Cult. Sci. Sport 12, 67-75. doi: $10.12800 /$ ccd.v12i34.833

Cresswell, J. W., and Plano Clark, V. L. (2011). Designing and Conducting Mixed Method Research, 2nd Edn, Vol. 5. Thousand Oaks, CA: Sage Publications.

Cronbach, L. J., Gleser, G. C., Nanda, H., and Rajaratnam, N. (1972). The Dependability of Behavioral Measurements: Theory of Generalizability for Scores and Profiles. New York: John Wiley and Sons.

Dutt, A., Aghabozrgi, S., Ismail, M. A. B., and Mahroeian, H. (2015). Clustering algorithms applied in educational data mining. Int. J. Inf. Electron. Eng. 5, 112-116. doi: 10.7763/IJIEE.2015.V5.513

Hernández-Mendo, A., and Anguera, M. T. (1999). "Contributions of polar coordinate analysis to team sports," in La Psicología del Deporte en España al final del milenio, eds F. Guillén (Las Palmas: University of Las Palmas de Gran Canaria), 169-175.
Hernández-Mendo, A., Blanco-Villaseñor, A., Pastrana, J. L., Morales-Sánchez, V., and Ramos-Pérez, F. J. (2016). SAGT: a computer application for generalizability analysis. Iberoamerican J. Exerc. Sport Psychol. 11, 77-89.

Hernández-Mendo, A., Castellano, J., Camerino, O., Jonsson, G., BlancoVillaseñor, A., Lopes, A., and Anguera, M. T. (2014). Software for re-recording, data quality control, and data analysis. J. Sport Psychol. 23, 111-121.

Hernández-Mendo, A., González, S., Ortega, M. A., Ortega, J., and Rondán, R. (2000). "Contributions of sequential analysis to basketball: an approach," in Lecturas: Physical Education and Sports, 18. Retrieved from: http://www. efdeportes.com/efd18/analis.htm

Hernández-Mendo, A., López, J. A., Castellano, J., Morales-Sánchez, V., and Pastrana, J. L. (2012). Hoisan 1.2: Software for use in observational methodology. Cuad. Psicol. Deporte 12, 55-77. doi: $10.4321 /$ S1578-84232012000100006

Kaur, D., Bedi, R., and Gupta, S. K. (2015). "Review of decision tree data mining algorithms: ID3 and C4. 5," in Proceedings of the International Conference on Information Technology and Computer Science.

Koutsouridis, C., Karamousalidis, G., and Galazoulas, C. (2018). The efficacy of "High Pick and Roll" in relation to the defence's reaction and its effect on the result of the game. Int. J. Perform. Anal. Sport 18,. 554-567 doi: 10.1080/24748668.2018.1501983

Likas, A., Vlassis, N., Verbeek, J. J. (2003). The global k-means clustering algorithm. Pattern Recogn. 36, 451-461. doi: 10.1016/S0031-3203(02)00060-2

Mateus, N., Gonçalves, B., Exel, J., Esteves, P., and Sampaio, J. (2020). Short-term effects of adding 1-m wide to each side of the basketball court on youth players' performance. Cuad. Psicol. Deporte 20, 82-94. doi: 10.6018/cpd.376321

Mateus, N., Gonçalves, B., Weldon, A., and Sampaio, J. (2019). Effects of using four baskets during simulated youth basketball games. PLoS ONE 14:e0221773. doi: 10.1371/journal.pone.0221773

Morales Toapanta, B. H., Pérez Ruíz, M. E., Pillajo Peralta, M. A., Bonilla López, A. R., Romero Frómeta, E., and Morán Pedroso, L. (2018). Biomechanical differences and effectiveness of basketball free throw shooting in this optimum and in fatigue. Cuban J. Biomed. Res. 37, 1-4.

Morales-Sánchez, V., Pérez-López, R., Reigal, R. E., and Hernández-Mendo, A. (2020). Mixed-methods analysis of emotional quality in sports organizations: facial expressions of child users of sports services as data. Front. Psychol. 11:1199. doi: 10.3389/fpsyg.2020.01199

Morillo-Baro, J. P., Moreno Pastor, A., Reigal Garrido, R. E., Vázquez-Diz, J. A. and Hernández-Mendo, A. (2020). "Decision making in professional basketball Pick and Pop: Polar Coordinates analysis," in Psicología del deporte y ciencias aplicadas (Monterrey: Fondo Editorial de Nueva León), 911-939.

Muñoz Arroyave, V., Serna Bardavio, J., Daza Sobrino, J., and Hileno González, R. (2015). Influence of direct blocking and one-on-one in the success of shooting in basketball. Apunts. Phys. Educ. Sport 199, 80-86. doi: 10.5672/apunts.2014-0983.cat.(2015/1).119.05

Nunes, H., Iglesias, X., and Anguera, M. T. (2021). Decision making and defensive effectiveness of ball screen in top-level basketball. Revista De Psicología Del Deporte (J. Sport Psychol.), 30, 208-222. Retrieved from: https://www.rpdonline.com/index.php/rpd/article/view/369

Nunes, H., Iglesias, X., Daza, G., Irurtia, A., Caparrós, T., and Anguera, M. T. (2016). Influence of the pick and roll on the attacking game in high-level basketball. Cuad. Psicol. Deporte 16, 129-142.

Pastrana, J. L., Reigal, R. E., Morales-Sánchez, V., Morillo-Baro, J. P., Juárez-Ruiz de Mier, R., Alves, J., and Hernández-Mendo, A. (2019). Data mining in the mixed methods: application to the study of the psychological profiles of athletes. Front. Psychol. 10:2675. doi: 10.3389/fpsyg.2019.02675

Reigal, R. E., Pastrana-Brincones, J. L., González-Ruiz, S. L., Hernández-Mendo, A., Morillo-Baro, J. P., and Morales-Sánchez, V. (2020). Use of data mining to determine usage patterns of an online evaluation platform during the COVID19 pandemic. Front. Psychol. 11:588843. doi: 10.3389/fpsyg.2020.588843

Rodríguez López, A., and Sáez Rodríguez, G. (2009). Análisis de los efectos de la concetración en el tiro libre en baloncesto. Cuad. Psicol. Deporte 9:80.

Rodríguez-Medina, J., Arias, V., Arias, B., Hernández-Mendo, A., and Anguera, M. T. (2019). Polar Coordinate Analysis, from HOISAN to R: A Tutorial Paper. Unpublished manuscript. Available online at: https://jairodmed.shinyapps.io/ HOISAN_to_R/ (accessed February 27, 2021).

Romarís Durán, I. U. (2016). Most Relevant Tactical Actions in the Outcome of Possessions in Basketball as a Function of the System of Play in Attack and 
Defense. Unpublished PhD thesis. University of A Coruña, Faculty of Sports Science and Physical Education.

Romarís Durán, I. U., Refoyo, I., and Coterón, J. (2013). The completion of possessions in basketball: a study of the finishing action. Cuad. Psicol. Deporte 12, 45-50. doi: 10.4321/S1578-84232012000300011

Sackett, G. P. (1980). "Lag Sequential Analysis as a data reduction technique in social interaction research," in Exceptional Infant. Phychosocial Risksin InfantEnvironment Transactions, eds D. B. Sawin, R. C. Hawkins, L. O. Walker, and J. H. Penticuff (New York: Brunner/Mazel), 300-340.

Sánchez-Algarra, P., and Anguera, M. T. (2013). Qualitative/quantitative integration in the inductive observational study of interactive behavior: impact of recording and coding predominating perspectives. Qual. Quant. 47, 1237-1257. doi: 10.1007/s11135-0129764-6

Sarmento, H., Anguera, M. T., Campaniço, J., and Leitão, J. (2010). Development and validation of a notational system of studythe offensive process in football. Medicina 46, 401-407. doi: 10.3390/medicina46060056

Sarmento, H., Clemente, P. M., Araújo, D., Davids, K., McRobert, A., and Figueiredo, A. (2017). What performance analysts need to know about research trens in Association Football (2012-2016). Sports Med. 48, 799-836. doi: 10.1007/s40279-017-0836-6

Sekulić, M. (2021). "Evaluation of Pick and Roll in Elite Basketball," in International Conference of Sport Science-AESA (Vol. 5, No. 2).

Thomas, M. C., Zhu, W., and Romagnoli, J. A. (2018). Data mining and clustering in chemical process databases for monitoring and knowledge discovery. J. Process. Control 67, 160-175. doi: 10.1016/j.jprocont.2017. 02.006

Vázquez-Diz, J. A., Morillo-Baro, J. P., Reigal, R. E., Morales-Sánchez, V., and Hernández-Mendo, A. (2019). Mixed methods in decision-making through polar coordinate technique: differences by gender on beach handball specialist. Front. Psychol. 10:1627. doi: 10.3389/fpsyg.2019. 01627

Weka 3 (2021). Machine Learning Software in Java. Available online at: https:// www.cs.waikato.ac.nz/ml/weka/ (accessed March 03, 2021).

Witten, I. H., Frank, E., Hall, M. A., and Pal, C. J. (2016). Data Mining: Practical Machine Learning Tools and Techniques. San Francisco: Morgan Kaufmann.

Zaki, M. J., and Meira, W. Jr. (2014). Data Mining and Analysis: Fundamental Concepts and Algorithms. Cambridge: Cambridge University Press.

Conflict of Interest: The authors declare that the research was conducted in the absence of any commercial or financial relationships that could be construed as a potential conflict of interest.

Publisher's Note: All claims expressed in this article are solely those of the authors and do not necessarily represent those of their affiliated organizations, or those of the publisher, the editors and the reviewers. Any product that may be evaluated in this article, or claim that may be made by its manufacturer, is not guaranteed or endorsed by the publisher.

Copyright @ 2021 Morillo-Baro, Troyano-Gallegos, Pastrana-Brincones, VázquezDiz, Reigal, Quiñones-Rodríguez, Hernández-Mendo, Falcó and Morales-Sánchez. This is an open-access article distributed under the terms of the Creative Commons Attribution License (CC BY). The use, distribution or reproduction in other forums is permitted, provided the original author(s) and the copyright owner(s) are credited and that the original publication in this journal is cited, in accordance with accepted academic practice. No use, distribution or reproduction is permitted which does not comply with these terms. 